九州大学学術情報リポジトリ

Kyushu University Institutional Repository

\title{
Variation on Grain Quality in Vietnamese Rice Cultivars Collected from Central Vietnam
}

\section{Tran, Danh Suu}

Plant Resources Center, Vietnam Academy of Agricultural Science (VAAS), Ankhanh, Hoaiduc, Hanoi City, Vietnam

\section{Tran, Thi Thu Hoai}

Laboratory of Plant Genetic Resources, Institute of Genetics Resources, Faculty of Agriculture, Kyushu University | Plant Resources Center, Vietnam Academy of Agricultural Science (VAAS), Ankhanh, Hoaiduc, Hano i City, Vietnam

Nguyen, Thi Lan Hoa

Plant Resources Center, Vietnam Academy of Agricultural Science (VAAS), Ankhanh, Hoaiduc, Hanoi City, Vietnam

Ha, Minh Loan

Plant Resources Center, Vietnam Academy of Agricultural Science (VAAS), Ankhanh, Hoaiduc, Hanoi City, Vietnam

他

https://doi.org/10.5109/25192

出版情報：九州大学大学院農学研究院紀要. 57 (2)，pp. 365-371，2012-09-20. Faculty of Agriculture, Kyushu University

バージョン :

権利関係 : 


\title{
Variation on Grain Quality in Vietnamese Rice Cultivars Collected from Central Vietnam
}

\section{TRAN Danh Suu ${ }^{1 *}$, TRAN Thi Thu Hoai ${ }^{1,2}$, NGUYEN Thi Lan Hoa ${ }^{1}$, HA Minh Loan ${ }^{1}$, DINH Bach Yen ${ }^{1}$, Toshihiro KUMAMARU ${ }^{2}$ and Hikaru SATOH ${ }^{2}$}

\author{
Laboratory of Plant Genetic Resources, Institute of Genetics Resources, Faculty of Agriculture, \\ Kyushu University, Fukuoka 812-8581, Japan \\ (Received March 26, 2012 and accepted May 10, 2012)
}

\begin{abstract}
Characterization of grain quality of rice germplasm is important for broadening the genetic base for breeding program. In this study, we characterize the grain size and apparent amylose content of ninety eight rice cultivars which collected from Central of Vietnam. The endosperm types of ninety eight Vietnamese rice cultivars were classified as waxy, opaque, white core and translucency, and GBSS level were divided into four groups, including absent, low, intermediate and high. In non-waxy group, the wide variation of apparent amylose content was observed in thirty four rice cultivars. The continuous variation on the apparent amylose content was observed in three respective groups of GBSS. The grain length showed the positive correlation with apparent amylose content while grain width showed negative correlation. The very low amylose class was not found in two regions including Central highland and South coastal central whereas the intermediate amylose class was not detected in the North central region of Vietnam.
\end{abstract}

Keywords: amylose, GBSS, genetic resources, grain quality, rice

\section{INTRODUCTION}

Rice (Oryza sativa L.) is one of the most important crops in the world, providing staple food for nearly one half of the global population. Particularly in Asia, rice provides 50-60\% of dietary energy supply. Quality of rice is determined by key components such as appearance, milling quality, cooking and eating quality, and nutritional quality. The grain length, grain width, grain shape and endosperm type are important quality traits which greatly effects commercial value of grain. Previous studies reported that the grain shape is quantitatively inherited (Kuo and Hsien, 1982; Chen et al., 1998). To obtain different combination of allele conferring particular grain shapes and size has implications for yield improvement (Melissa et al., 2008). A great diversity of grain size and shape found in rice resources (Koutroubas et al., 2003; Zeng et al., 2003) suggested that the local rice germplasm may play an important role in improving rice quality.

Comprise up 90 percent of milled rice, endosperm starch plays a critical role in eating and cooking quality of rice. The physicochemical properties of rice starch are affected by the ratio of amylose to amylopectin (Larkin et al., 2003) and the structure of starch molecule (Nakamura et al., 2006). Amylose is considered the most important predictor of sensory quality in rice, which is essentially linear polymer of $\alpha-1,4$ linked glycosidic chain.

Starch biosynthesis is catalysed by at least four classes of enzymes: Adenosine disphosphate glucose pyrophosphorylase (AGPase), starch synthase (SS),

Plant Resources Center, Vietnam Academy of Agricultural Science (VAAS), Ankhanh, Hoaiduc, Hanoi City, Vietnam

Laboratory of Plant Genetic Resources, Institute of Genetics Resources, Faculty of Agriculture, Kyushu University, Fukuoka 812-8581, Japan

* Corresponding author (E-mail: trandanh_suu@yahoo.com) starch branching enzyme (BE), and starch debranching enzyme (DBE) (Smith et al., 1997; Myers et al., 2000; Nakamura, 2002, Satoh et al., 2007; Hannah and James, 2008). The waxy gene, which encodes the granulebound starch synthase (GBSS), is one key gene influencing starch synthesis in the rice endosperm (Larkin and Park, 2003). There are several alleles encoded by the $W x$ locus involved in amylose content, (Chen et al., 2008, Mikami et al., 2008). The allele $W x^{a}$ has been recognized as being distributed in Indica while the allele $W x^{b}$ is distributed in Japonica subspecies (Sano, 1984; Isshiki et al., 1998). Mikami et al. (2008) reported that an SNP in exon 6, which is identified as $W x^{\text {in }}$ allele, separating high and intermediate amylose varieties. An SNP in exon 4, which associates with opaque phenotype, is defined as the $W x^{\text {op }}$ allele. Furthermore, mutants with low amylose content with dull endosperm, called "dull" mutant, were characterized (Yano et al., 1988; Satoh et al., 2003; Satoh et al., 2004). The waxy mutants carry a deletion in the $W x$ gene that is fatal to activity of GBSS, and consequently they contain no amylose (Mikami et $a l ., 1999)$. The spontaneous mutation of amylose were found in local rice cultivars from Asian and African countries (Nakagahara and Nagamine, 1986; Satoh et al., 1990; Jahan et al., 2002, Hoai et al., 2008).

Central and Northern mountainous areas in Vietnam are considered to be the regions of richness in rice genetic resources (Chang, 1976; Okuno et al., 1996). Therefore, in this study we investigated the variation on grain quality in rice cultivars from Central Vietnam for promoting utilization and improvement of high quality rice varieties.

\section{MATERIALS AND METHODS}

\section{Plant materials}

Ninety eight rice cultivars collected from three regions of Central Vietnam were used in this study. Three 
rice cultivars including IR36 (Indica), TC65 (Japonica) and EM21 (waxy mutant) were used as controls.

\section{Variation in morphological character and measure- ment of grain size}

Based on the rice descriptors of IRRI, variation on endosperm type was characterized. The endosperm type was classified as 4 scales including waxy, opaque, white core and translucency. Three characters including grain length, grain width and the ratio grain length per grain width have been conducted.

\section{Determine the apparent amylose content}

Amylose content was estimated by using the DU 7500 Spectrophotometer (Beckman) according to Satoh (1990e).

\section{GBSS extraction and SDS-PAGE analysis}

GBSS was isolated from the polished rice flour according to Echt and Schwartz (1981). $20 \mathrm{mg}$ rice flour was homogenized in $1.5 \mathrm{ml}$ of GBSS-extraction buffer (0.055M Tris-HCl, 2.5\% SDS (w/v), 5\% 2-mercaptoetanol adjusted at $\mathrm{pH}$ 6.8). The suspension was sonicated and centrifuged at 1,200 rpm for 5 minutes. After washing three times with GBSS-extraction buffer and twice in the distilled water, the pellet was dissolved in 2-mercaptoetanol adjusted at $\mathrm{pH} 6.8$. The sample was centrifuged at 1,200 rpm for 10 minutes and the resulting supernatant was loaded on a $10 \%$ polyacrylamide gel. SDS-PAGE was performed according to Laemmli (1970) using 10\% polyacrylamide gel. $60 \mathrm{kD}$ band corresponding to GBSS could be seen by Coomassie Brilliant Blue staining and was measured by a densitometer. The GBSS level was classified as high, intermediate and low and absent based on staining intensity of $60 \mathrm{kD}$.

\section{Western blotting}

$700 \mu \mathrm{l}$ SDS-PAGE sample buffers was added to each $20 \mathrm{mg}$ sample and then vortex for 3 hours at room temperature, centrifuged at $20^{\circ} \mathrm{C}, 6,000$ to $7,000 \mathrm{rpm}$ in 10 minutes. SDS-PAGE was performed by using $10 \%$ SDS polyacrylamide gel. The PVDF membrane was used for blotting the band of proteins and the membrane was incubated with the primary antibody (GBSS-anti wheat waxy protein). Immunoreactive proteins were detected by incubating the secondary antibody. Goat Anti-rabbit IgG H+L. Equal amount of the ECL substrate was mixed and the membrane was incubated for $1 \mathrm{~min}$ in this mixture before using. The X-ray film was developed, washed and fixed.

\section{RESULTS}

\section{Morphological variation of grain size}

Length of grain ranged from $7.26 \mathrm{~mm}$ to $11.56 \mathrm{~mm}$ among 98 rice cultivars. They were divided into two

Table 1. Vietnamese rice examined for grain type (grain length, grain width, endosperm type), apparent amylose content and GBSS level

\begin{tabular}{|c|c|c|c|c|c|c|c|}
\hline Cultivar name & $\begin{array}{l}\text { Collection } \\
\text { site }\end{array}$ & $\begin{array}{l}\text { Grain length } \\
\quad(\mathrm{mm})\end{array}$ & $\begin{array}{l}\text { Grain width } \\
\text { (mm) }\end{array}$ & $\mathrm{L} / \mathrm{W}$ ratio & $\begin{array}{l}\text { Endosperm } \\
\text { Type }\end{array}$ & $\begin{array}{l}\text { Apparent amylose } \\
\text { content (\%) }\end{array}$ & GBSS level \\
\hline Nep cam dang 1 & NC & 9.98 & 3.76 & 2.65 & Waxy & 3.42 & absent \\
\hline Vang me & $\mathrm{NC}$ & 9.82 & 3.56 & 2.76 & Opaque & 11.4 & low \\
\hline Lua song & $\mathrm{NC}$ & 8 & 3.7 & 2.16 & Waxy & 5.7 & absent \\
\hline Nep hat cau dang 1 & $\mathrm{NC}$ & 7.54 & 3.86 & 1.95 & Waxy & 1.9 & absent \\
\hline Nep vang som & $\mathrm{NC}$ & 8.56 & 3.7 & 2.31 & Waxy & 2.66 & absent \\
\hline Nep ech dang 1 & NC & 7.98 & 4.72 & 1.69 & Waxy & 1.14 & absent \\
\hline Cam vo vang & $\mathrm{NC}$ & 9.66 & 3.02 & 3.20 & Waxy & 0.76 & absent \\
\hline Nep truong & $\mathrm{NC}$ & 8.4 & 4.58 & 1.83 & Waxy & 3.8 & absent \\
\hline Cham song & $\mathrm{NC}$ & 8.1 & 3.64 & 2.23 & Translucency & 14.82 & low \\
\hline Nep tron & $\mathrm{NC}$ & 8.92 & 3.66 & 2.44 & Waxy & 2.66 & absent \\
\hline Nep cai rau & $\mathrm{NC}$ & 7.48 & 3.64 & 2.05 & Waxy & 5.32 & absent \\
\hline Nep cai can & NC & 7.96 & 4.56 & 1.75 & Waxy & 3.04 & absent \\
\hline Lua dam xoong & $\mathrm{NC}$ & 8.28 & 3.32 & 2.49 & White core & 15.58 & low \\
\hline But veng & $\mathrm{NC}$ & 8.44 & 3.22 & 2.62 & Waxy & 3.8 & absent \\
\hline But kia & $\mathrm{NC}$ & 9.32 & 3.24 & 2.88 & White core & 13.68 & low \\
\hline Nep cam den & $\mathrm{NC}$ & 9.78 & 3.56 & 2.75 & Waxy & 5.32 & absent \\
\hline Nep cam & $\mathrm{NC}$ & 9.92 & 3.88 & 2.56 & Opaque & 14.82 & low \\
\hline Te mun & $\mathrm{NC}$ & 9.76 & 3.14 & 3.11 & Waxy & 3.42 & absent \\
\hline Nep thuong & $\mathrm{NC}$ & 8.34 & 3.8 & 2.19 & Waxy & 1.52 & absent \\
\hline Te nuong & $\mathrm{NC}$ & 8.42 & 3.52 & 2.39 & White core & 13.3 & low \\
\hline Lo cang & $\mathrm{NC}$ & 9.04 & 3.28 & 2.76 & Waxy & 1.52 & absent \\
\hline Lo xo & $\mathrm{NC}$ & 10.46 & 3.62 & 2.89 & Waxy & 4.94 & absent \\
\hline Lo cam & $\mathrm{NC}$ & 8 & 3.28 & 2.44 & White core & 29.64 & high \\
\hline Nep cu dat & $\mathrm{NC}$ & 7.26 & 3.32 & 2.19 & Waxy & 5.32 & absent \\
\hline Cu man & $\mathrm{NC}$ & 7.56 & 3.66 & 2.07 & Waxy & 0.38 & absent \\
\hline Sang chu & $\mathrm{NC}$ & 8.38 & 4.64 & 1.81 & Waxy & 3.04 & absent \\
\hline
\end{tabular}


Table 1. Continued

\begin{tabular}{|c|c|c|c|c|c|c|c|}
\hline Cultivar name & $\begin{array}{l}\text { Collection } \\
\text { site }\end{array}$ & $\begin{array}{l}\text { Grain length } \\
\quad(\mathrm{mm})\end{array}$ & $\begin{array}{l}\text { Grain width } \\
\text { (mm) }\end{array}$ & $\mathrm{L} / \mathrm{W}$ ratio & $\begin{array}{l}\text { Endosperm } \\
\text { Type }\end{array}$ & $\begin{array}{l}\text { Apparent amylose } \\
\text { content (\%) }\end{array}$ & GBSS level \\
\hline Nep bo giua & $\mathrm{NC}$ & 9.6 & 3.56 & 2.70 & Waxy & 3.04 & absent \\
\hline Boc bo & $\mathrm{NC}$ & 9.44 & 3.52 & 2.68 & Waxy & 2.66 & absent \\
\hline Nep man & $\mathrm{NC}$ & 9.54 & 3.64 & 2.62 & Waxy & 4.94 & absent \\
\hline Luot cay & $\mathrm{NC}$ & 8.22 & 3.5 & 2.35 & Waxy & 5.32 & absent \\
\hline Khau cho lon & $\mathrm{NC}$ & 9.7 & 3.74 & 2.59 & Waxy & 4.94 & absent \\
\hline Khau cam panh & $\mathrm{NC}$ & 10.58 & 3.56 & 2.97 & Waxy & 2.66 & absent \\
\hline Khau ma giang & $\mathrm{NC}$ & 8.96 & 3.44 & 2.60 & Waxy & 0.38 & absent \\
\hline Khau non & $\mathrm{NC}$ & 10.18 & 3.3 & 3.08 & Waxy & 4.94 & absent \\
\hline Khau hin & $\mathrm{NC}$ & 7.98 & 3.76 & 2.12 & Waxy & 1.14 & absent \\
\hline Khau vai nieu & $\mathrm{NC}$ & 9.58 & 3.64 & 2.63 & Waxy & 0.76 & absent \\
\hline Khau moong mo & $\mathrm{NC}$ & 9.26 & 3.66 & 2.53 & Waxy & 0.76 & absent \\
\hline Khau chao den & $\mathrm{NC}$ & 9.26 & 3.42 & 2.71 & White core & 29.26 & high \\
\hline Khau cham cam & $\mathrm{NC}$ & 8.02 & 3.12 & 2.57 & White core & 26.22 & high \\
\hline Khau luong cuoi & $\mathrm{NC}$ & 10.26 & 3.12 & 3.29 & Waxy & 1.52 & absent \\
\hline Chao luu & $\mathrm{NC}$ & 8.04 & 3.6 & 2.23 & White core & 15.58 & low \\
\hline Khau luong con & $\mathrm{NC}$ & 7.6 & 3.98 & 1.91 & Waxy & 1.52 & absent \\
\hline Khau san & $\mathrm{NC}$ & 8.84 & 3.74 & 2.36 & Waxy & 1.52 & absent \\
\hline Khau vai do & $\mathrm{NC}$ & 10 & 3.9 & 2.56 & Waxy & 0.76 & absent \\
\hline Khau do don & $\mathrm{NC}$ & 9.02 & 3.58 & 2.52 & Waxy & 3.42 & absent \\
\hline Khau danh dan & $\mathrm{NC}$ & 9.46 & 3.5 & 2.70 & Waxy & 3.42 & absent \\
\hline Khau cam & $\mathrm{NC}$ & 8.76 & 3.84 & 2.28 & Waxy & 1.52 & absent \\
\hline Chao meo & $\mathrm{NC}$ & 9.16 & 2.98 & 3.07 & Opaque & 10.64 & low \\
\hline Khau pan & $\mathrm{NC}$ & 9.32 & 3.7 & 2.52 & Waxy & 1.14 & absent \\
\hline Ngoo vai & $\mathrm{NC}$ & 10.12 & 3.06 & 3.31 & Waxy & 3.04 & absent \\
\hline Ngoo nac & $\mathrm{NC}$ & 10.16 & 3.64 & 2.79 & Waxy & 1.14 & absent \\
\hline Khau chao vai & $\mathrm{NC}$ & 9.36 & 2.8 & 3.34 & White core & 14.82 & low \\
\hline Khau do sang & $\mathrm{NC}$ & 8.28 & 3.8 & 2.18 & Waxy & 1.52 & absent \\
\hline Khau pa pan & $\mathrm{NC}$ & 9.76 & 3.72 & 2.62 & Waxy & 3.42 & absent \\
\hline Nep lau & $\mathrm{NC}$ & 10.08 & 3.36 & 3.00 & Waxy & 5.32 & absent \\
\hline Nep rang chau & $\mathrm{NC}$ & 9.4 & 3.98 & 2.36 & Waxy & 4.94 & absent \\
\hline Nep man & $\mathrm{NC}$ & 8.36 & 3.56 & 2.35 & Waxy & 4.56 & absent \\
\hline Nep thai & $\mathrm{NC}$ & 10.12 & 3.04 & 3.33 & Waxy & 5.32 & absent \\
\hline Nep chac rat & $\mathrm{NC}$ & 8.48 & 3.66 & 2.32 & Waxy & 3.42 & absent \\
\hline Khau lac & $\mathrm{NC}$ & 9.22 & 3.46 & 2.66 & Waxy & 3.42 & absent \\
\hline Khau cu & $\mathrm{NC}$ & 8.7 & 3.92 & 2.22 & Waxy & 1.14 & absent \\
\hline Khau pe lanh & $\mathrm{NC}$ & 9.6 & 3.02 & 3.18 & Waxy & 1.14 & absent \\
\hline Cham nanh & $\mathrm{NC}$ & 8.86 & 3.2 & 2.77 & White core & 11.78 & low \\
\hline Cham noi & $\mathrm{NC}$ & 9.42 & 3.2 & 2.94 & White core & 13.3 & low \\
\hline Khau tao & $\mathrm{NC}$ & 10.14 & 3.54 & 2.86 & Waxy & 4.94 & absent \\
\hline Lep muoi & $\mathrm{NC}$ & 8.76 & 4.04 & 2.17 & Waxy & 1.9 & absent \\
\hline Knon & $\mathrm{NC}$ & 10.38 & 2.94 & 3.53 & Waxy & 5.7 & absent \\
\hline Cu hon & $\mathrm{NC}$ & 8.42 & 3.44 & 2.45 & Waxy & 5.7 & absent \\
\hline Nhan pung & $\mathrm{NC}$ & 9.78 & 4.06 & 2.41 & Waxy & 3.42 & absent \\
\hline Lua na & SCC & 8.26 & 3.12 & 2.65 & White core & 25.46 & high \\
\hline Ca do & SCC & 9.66 & 3.52 & 2.74 & Translucency & 20.9 & high \\
\hline Nep tro & SCC & 9.24 & 3.34 & 2.77 & Waxy & 3.8 & absent \\
\hline Lua nhe & SCC & 8.7 & 3.04 & 2.86 & Translucency & 25.46 & high \\
\hline A hach & SCC & 10.02 & 2.72 & 3.68 & Translucency & 27.74 & high \\
\hline $\mathrm{Ca}$ ang & SCC & 9.82 & 2.72 & 3.61 & Translucency & 27.74 & high \\
\hline A vay & SCC & 9.36 & 2.62 & 3.57 & White core & 17.48 & intermediate \\
\hline Nep den & SCC & 8.52 & 2.96 & 2.88 & Waxy & 3.8 & absent \\
\hline Nep bo & SCC & 9.62 & 2.32 & 4.15 & Waxy & 5.32 & absent \\
\hline Djang kloih & $\mathrm{CH}$ & 9.76 & 3.6 & 2.71 & White core & 22.42 & high \\
\hline Me loll & $\mathrm{CH}$ & 9.82 & 3.54 & 2.77 & White core & 19.38 & intermediate \\
\hline M bat & $\mathrm{CH}$ & 9.86 & 2.66 & 3.71 & Opaque & 13.68 & low \\
\hline Coi tung rling dạng 1 & $\mathrm{CH}$ & 9.9 & 3.12 & 3.17 & Translucency & 22.42 & high \\
\hline Koi djang wir & $\mathrm{CH}$ & 11.56 & 2.54 & 4.55 & Translucency & 28.12 & high \\
\hline M bet dang & $\mathrm{CH}$ & 11.34 & 2.6 & 4.36 & Waxy & 3.42 & absent \\
\hline
\end{tabular}




\begin{tabular}{lccccccc}
\hline Table 1. Continued & \multicolumn{1}{c}{} & & & & \\
\hline \multicolumn{1}{c}{ Cultivar name } & $\begin{array}{c}\text { Collection } \\
\text { site }\end{array}$ & $\begin{array}{c}\text { Grain length } \\
(\mathrm{mm})\end{array}$ & $\begin{array}{c}\text { Grain width } \\
(\mathrm{mm})\end{array}$ & L/W ratio & $\begin{array}{c}\text { Endosperm } \\
\text { Type }\end{array}$ & $\begin{array}{c}\text { Apparent amylose } \\
\text { content (\%) }\end{array}$ & GBSS level \\
\hline Koi me loh & $\mathrm{CH}$ & 9.2 & 3.1 & 2.97 & White core & 24.7 & intermediate \\
M bet krop & $\mathrm{CH}$ & 10.4 & 3.66 & 2.84 & Waxy & 5.7 & absent \\
Koi N ken & $\mathrm{CH}$ & 10.04 & 3.12 & 3.22 & White core & 22.8 & high \\
Koi soai & $\mathrm{CH}$ & 9.98 & 2.86 & 3.49 & Translucency & 15.2 & low \\
Koi koe & $\mathrm{CH}$ & 9.46 & 3.2 & 2.96 & Translucency & 15.96 & low \\
Ba keen & $\mathrm{CH}$ & 10.64 & 2.74 & 3.88 & Translucency & 15.2 & low \\
Ba ke & $\mathrm{CH}$ & 10.4 & 2.74 & 3.80 & Translucency & 14.82 & low \\
Ba lo & $\mathrm{CH}$ & 9.62 & 3.62 & 2.66 & White core & 17.48 & intermediate \\
Ba N kon & $\mathrm{CH}$ & 9.42 & 3.26 & 2.89 & White core & 21.66 & high \\
Ba M bet dia & $\mathrm{CH}$ & 8.92 & 3.2 & 2.79 & Waxy & 5.7 & absent \\
Ba M bet ler & $\mathrm{CH}$ & 9.98 & 3.26 & 3.06 & Waxy & 5.32 & absent \\
Nep heo & $\mathrm{CH}$ & 11.54 & 2.64 & 4.37 & Waxy & 2.66 & absent \\
Nep heo & $\mathrm{CH}$ & 10.96 & 2.78 & 3.94 & Waxy & 3.42 & absent \\
Lua rau & $\mathrm{CH}$ & 9.88 & 2.96 & 3.34 & Translucency & 25.46 & high \\
IR 36 & & 8.84 & 2.42 & 3.65 & Translucency & 23.56 & high \\
Nipponbare & & 7.6 & 3.12 & 2.44 & Translucency & 20.14 & low \\
\hline
\end{tabular}

CH: Central Highland; NC: North Central; SCC: South Coastal Central

Table 2. Variation on the length-to-width ratio in Central Vietnamese rice cultivars

\begin{tabular}{|c|c|c|c|}
\hline Scale & $\mathrm{L} / \mathrm{W}$ ratio & $\begin{array}{c}\text { Number of } \\
\text { cultivars }\end{array}$ & $\begin{array}{c}\text { Frequency } \\
(\%)\end{array}$ \\
\hline 1 & Bold (1.1-2.0) & 6 & 6 \\
\hline 2 & Medium (2.1-3.0) & 66 & 67 \\
\hline 3 & Slender $(>3.0)$ & 26 & 27 \\
\hline & Total & 98 & 100 \\
\hline
\end{tabular}

Table 3. Distribution of endosperm type in Central Vietnam rice cultivars

\begin{tabular}{clcr}
\hline Scale & Endosperm types & $\begin{array}{c}\text { Number of } \\
\text { cultivars }\end{array}$ & $\begin{array}{c}\text { Frequency } \\
(\%)\end{array}$ \\
\hline 1 & Waxy & 64 & 65 \\
2 & Opaque & 4 & 4 \\
3 & White core & 18 & 18 \\
4 & Translucency & 12 & 12 \\
\hline & Total & 98 & 100 \\
\hline
\end{tabular}

groups: long grain (from 6.61 to $7.5 \mathrm{~mm}$ ) and very long grain (>7.5 mm). Most of cultivars (98\%) belonged to the very long grain group.

Variation of length-to-width ratio (L/W) was shown in Table 1 and Table 2. The length-to-width ratio (L/W) varied from 1.69 to 4.55 among 98 rice cultivars. Based on the ratio of grain length to grain width, 98 rice cultivars were grouped as bold (scale 1: 1.6-2.0), medium (scale 2: 2.1-3.0) and slender (scale 3: >3.0) with frequency $6 \%, 67 \%$ and $27 \%$, respectively.

Classification of non-waxy and waxy by endosperm type, iodine staining intensity and GBSS level

Endosperm type variation of 98 studied rice cultivars was shown in Table 1, Table 3 and Fig. 1A. The
A. Emdosperm type

1. Waxy 2. Opaque 3hite core 4. Translı

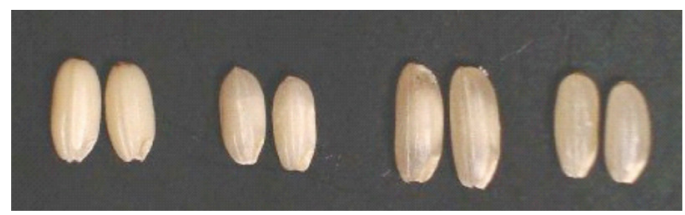

B. Iodine staining color of endosperm starch

$\begin{array}{lll}\text { EM21 } & \text { TC65 }\end{array}$
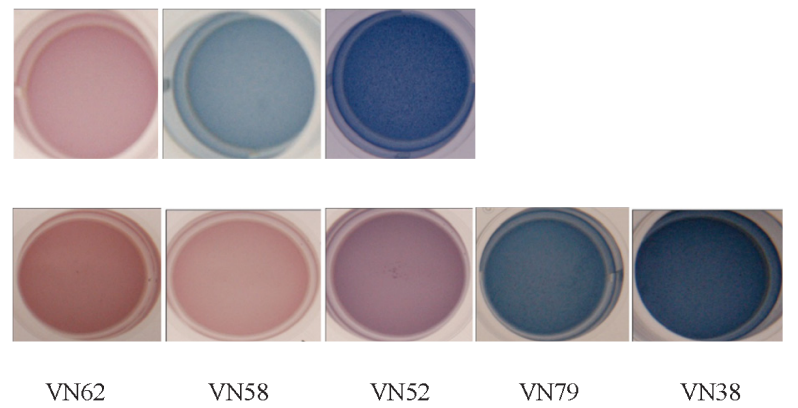

C. GBSS level by SDS-PAGE and Western blotting

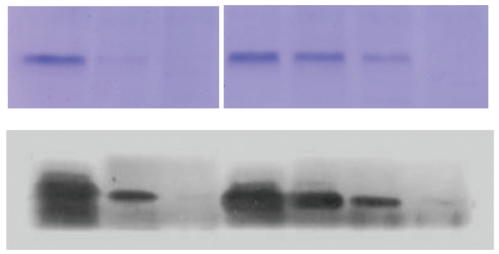

IR36 TC65 EM21 VN38 VN85 VN52 VN62

Fig. 1. Variation in endosperm type, iodine staining colour of endsperm starch and GBSS level among central Vietnam rice cultivars. 
endosperm types were classified as four scales including waxy, opaque, white core and translucency. The waxy endosperm type was found popular with frequency $65 \%$ of total cultivars. The opaque, white core and translucency were exhibited in $4 \%, 18 \%$ and $12 \%$ of total cultivars, respectively.

Ninety eight rice cultivars have I2-KI staining color varied from reddish, reddish brown, purple, purple to blue and dark blue (Fig. 1B). The waxy endosperm type had reddish color while other endosperm type showed the purple, purple to blue and dark blue ones.

The variation in GBSS level was observed among 98 samples (Fig. 1C). TC65 and IR36 were distinguished from each other by the staining intensity of $60 \mathrm{kDa}$. High

Table 4. Variation in apparent amylose content among Central Vietnam rice cultivars

\begin{tabular}{cccc}
\hline $\begin{array}{c}\text { Apparent amylose } \\
\text { content (\%) }\end{array}$ & $\begin{array}{c}\text { Amylose } \\
\text { class }\end{array}$ & $\begin{array}{c}\text { No of } \\
\text { cultivars }\end{array}$ & $\begin{array}{c}\text { Frequency } \\
(\%)\end{array}$ \\
\hline $0 \sim 6$ & Waxy & 64 & 65.3 \\
$6 \sim 12$ & Very low & 3 & 3.1 \\
$12 \sim 20$ & Low & 16 & 16.3 \\
$20 \sim 25$ & Intermediate & 6 & 6.1 \\
$>25$ & High & 9 & 9.2 \\
\hline Total & & 98 & 100 \\
\hline
\end{tabular}

intensity of GBSS $\left(W x^{a}\right)$ was found in IR36 while low intensity of GBSS $\left(W x^{b}\right)$ was found in TC65. GBSS was absent in EM21 $(W x)$. GBSS level of 98 rice cultivars were classified into four groups, including absent (EM21 type), low (TC65 type), intermediate (intermediate between TC65 and IR36) and high (IR36 type) with frequency of $65.3 \%, 16.3 \%, 4.1 \%$ and $14.3 \%$, respectively. All the waxy endosperm type of rice cultivars belonged to absent GBSS group.

\section{Variation in apparent amylose content in non-waxy rice}

In non-waxy group, the wide variation of apparent amylose content was observed in 34 rice cultivars (Table 1). The apparent amylose content in non- waxy rice varied from $10 \%$ to $29 \%$ and they were grouped into very low (10-12), low (12-20) high (20-25 and very high $(\geqq 25)$ with frequency $3.1 \%, 16.3 \%, 6.1 \%$ and $9.2 \%$ of total cultivars, respectively (Table 4).

\section{Relationship between apparent amylose content and GBSS level}

As mentioned above, waxy rice cultivars showed the absence of GBSS level. In non-waxy rice group, the correlation between the GBSS level and the apparent amylose content were observed in Table 5 . The continuous

Table 5. Distribution of Central Vietnam rice cultivars in GBSS level and apparent amylose content

\begin{tabular}{|c|c|c|c|c|c|c|c|}
\hline \multirow{2}{*}{ GBSS types } & \multicolumn{5}{|c|}{ Apparent amylose content (\%) } & \multirow{2}{*}{$\begin{array}{l}\text { Total of } \\
\text { cultivars }\end{array}$} & \multirow{2}{*}{$\begin{array}{c}\text { Frequency } \\
(\%)\end{array}$} \\
\hline & $0 \sim 6$ & $6 \sim 12$ & $12 \sim 20$ & $20 \sim 25$ & $>25$ & & \\
\hline Absent (waxy) & 64 & 0 & 0 & 0 & 0 & 64 & 65.3 \\
\hline Low & 0 & 3 & 13 & 0 & 0 & 16 & 16.3 \\
\hline Intermediate & 0 & 3 & 0 & 1 & 0 & 4 & 4.1 \\
\hline High & 0 & 0 & 0 & 5 & 9 & 14 & 14.3 \\
\hline Total & 64 & 6 & 13 & 6 & 9 & 98 & 100.0 \\
\hline
\end{tabular}

Table 6. The correlation of grain size and apparent amylose content

\begin{tabular}{ccccc}
\hline & Grain length & Grain width & L/W Ratio & \\
Grain length & 1 & & & \\
Grain width & -0.449 & -0.878 & 1 & 1 \\
L/W Ratio & 0.792 & -0.432 & 0.332 & 1 \\
Amylose content & 0.129 & & \\
\hline
\end{tabular}

Significant at $5 \%$.

Table 7. Regional distribution of Vietnamese local rice cultivars on apparent amylose content

\begin{tabular}{|c|c|c|c|c|c|}
\hline \multirow{2}{*}{ Amylose content (\%) } & \multicolumn{3}{|c|}{ Regions } & \multirow{2}{*}{ Total } & \multirow{2}{*}{ Frequency (\%) } \\
\hline & $\mathrm{CH}$ & $\mathrm{NC}$ & SCC & & \\
\hline Waxy $(0 \sim 6)$ & 6 & 55 & 3 & 64 & 65.3 \\
\hline Very low $(6 \sim 12)$ & 0 & 3 & 0 & 3 & 3.1 \\
\hline Low $(12 \sim 20)$ & 7 & 8 & 1 & 16 & 16.3 \\
\hline Intermediate (20 25) & 5 & 0 & 1 & 8 & 8.1 \\
\hline High $(>25)$ & 2 & 3 & 4 & 9 & 9.2 \\
\hline Total & 20 & 69 & 9 & 98 & 100 \\
\hline
\end{tabular}

CH: Central Highland; NC: North Central; SCC: South Coastal Central 
variation on the apparent amylose content was observed in three respective groups of GBSS. The low GBSS level cultivars had apparent amylose content varied from 10\% to $16 \%$, while intermediate and high GBSS cultivars showed the apparent amylose content from $17 \%$ to $24 \%$ and $20 \%$ to $29 \%$, respectively.

\section{Relationship between the grain length, grain width and grain shape and apparent amylose content}

The correlation of grain size and apparent amylose content was showed in Table 6. Grain length showed the positive correlation with apparent amylose content and grain shape while negative with grain width. Grain width showed negative correlation with apparent amylose content.

\section{Geographical distribution of rice cultivars on apparent amylose content}

Table 7 shows the regional distribution of rice cultivars on apparent amylose content. Each of three regions showed four per five amylose classes. The very low amylose class was not found in two regions including Central highland and South coastal central whereas the intermediate amylose class was not detected in the North Central. Waxy cultivars were found in all regions. However, almost waxy rice cultivars were distributed in North Central region (55 cultivars).

\section{DISSCUSSION}

The shape, uniformity and translucence of rice grain are important traits which define the market value. The value of each trait, for example grain length, varies according to local cuisine and culture (Melissa et al., 2008). Some studies on the variation of quality traits from rice germplasm have been reported. Koutroubas et al. (2003) showed that there was considerable genetic variation on grain length, grain width, grain length-to-width ratio and amylose content among 318 rice lines. Studying the variability in grain quality from 100 upland genotype India rice, Rathi et al. (2010) revealed the highly significant difference among the genotypes for grain size and other starch properties. In this study, almost of rice belonged to long grain length group while the medium is popular for grain shape (the length-to-width ratio) (Tables 1 and 2). The correlation between grain size and apparent amylose content in this research (Table 6) is in consistent with the finding of other research works (Chakraborty et al., 2009). The information on the relationship between rice grain shape and quality trait may be useful for developing selection indices in rice breeding program.

The waxy gene, which encoded the GBSS enzyme, is responsible for amylose synthesis in the rice endosperm. Some studies reported that the G-T single nucleotide polymorphism (SNP) at the 5' splice junction of the first intron is contributed to variation in the expression of the Waxy gene. Moreover, CT repeat and the SNP in exon 4, exon 6 and exon 10 are strong associated with different amylose class (Frances et al., 1998; Chen et al., 2008,
Mikami et al., 2008; Larkin and Park, 2003; Bao et al., 2008). In this study, the strong correlation between apparent amylose content and GBSS level was detected (Table 1). This continuous variation on the apparent amylose content may be caused by the intragenic variation of GBSS in addition to the amylopectin structure. Thus, rice cultivars from Central of Vietnam exhibited the high diversity both in GBSS level and apparent amylose content.

Some previous studies reported that the colorimetric method for estimating apparent amylose content is affected by the amylopectin structure (Nishi et al., 2001) and some rice amylopectin have long chain showing a high affinity for binding iodine (Takeda and Hizukuri, 1987). As mentioned above, sixty four waxy rice cultivars showed the variation in iodine staining intensity while they were observed absence of GBSS (Table 1 and Fig. 1B). This result suggested that the variation in iodine staining intensity among waxy rice was caused by the amylopectin structure.

The relation between amylose content and geographical distribution as well as GBSS level has been shown in several studies (Nakagahara and Nagamine, 1986; Jahan et al., 2002, Aung et al., 2003; Hoai et al., 2008; Liu et al., 2008). The geographical distribution of amylose content in 872 Asian rice cultivars from five Asian countries have been investigated by Nakagahara and Nagamine (1986). The clear difference in the pattern of geographical distribution on amylose content of rice cultivars from five countries was observed. Aung et al. (2002) reported that the variation in GBSS level and apparent amylose content in mountainous region was wider than these from other regions. When studying geographical distribution of GBSS level in 185 local rice cultivars from mountainous areas in Northern Vietnam, Hoai et al. (2008) reported the wide variation on apparent amylose content in Northwest and Northeast regions. The geographical distribution on apparent amylose content in this study was proved that Central region of Vietnam has rice germplasm with high variation on starch properties. Moreover, a huge number of waxy rice cultivars existed in this area supported that the Southeast Asian (encompassing portions of Lao, Myanmar, Thailand, Cambodia and Vietnam) are considered as the "glutinous rice zone" (Olsen and Purugganan, 2002).

\section{ACKNOWLEDGEMENTS}

This study was funded by the Vietnam's National Foundation for Science and Technology Development (NAFOSTED).

\section{REFERENCES}

Aung, P. P., A. Nishi, T. Kumamaru and H Satoh 2002 Genetic variation of granule-bound starch synthase (GBSS) level in Myanmar local rice cultivars. $R G N$., 19: 68-69

Bao, J. S., H. Corke and M. Sun 2006 Microsatellites, single nucleotide polymorphism and a sequence tagged site in starchsynthesizing genes in relation to starch physicochemical properties in nonwaxy rice (Oryza sativa L). Theor Appl Genet., 
113: $1185-1196$

Chakraborty, R., Chakraborty, S., Dutta, B. K. and S. B. Paul 2009 Genetic variability and genetic correlation among nutritional and cooking quality traits in bold grain rice. Oryza., 46(1): 21-25

Chang, T. T. 1976 The origin, evolution, cultivation, dissemination, and divergence of Asian and African rices. Euphytica., 25: $425-45$

Chen, J. G and J. Zhu 1998 Genetic effects and genotype x environment interactions for appearance quality traits in IndicaJaponica crosses for rice (Oryza sativa L.). Bot. Bull. Acad. Sinica., 22: 35-47

Chen, M. H., C. Bergman, S. Pinson and R. Fjellstrom 2008 Waxy gene haplotype: Associations with apparent amylose content and the effect by the environment in an international rice germplasm collection. J Cereal Sci., 47: 536-545

Chen, M. H., C. Bergman, S. Pinson and R. Fjellstrom 2008 Waxy gene haplotypea: Associations with pasting properties in an international rice germplasm collection. J Cereal Sci., 48: 781-788

Echt, C. S. and Schwartz, D. (1981) Evidence for the inclusion of controlling elements within the structural gene at the waxy locus in maize. Genetics 99: 275-284

Frances, H., J. Blight, P. D. Larkin, P. S. Roach, C. A. Janes, H. Fu and W. D. Park 1998 Use of alternate splice sites in granule-bound starch synthase mRNA from low-amylose rice varieties. Mol. Biol., 38: 407-415

Hannah, L. C and M. James 2008 The complexities of starch biosynthesis in cereal endosperms. Curr Opin Plant Biol., 19: $160-165$

Hoai, T. T., A. Nishi and H. Satoh 2008 Diversity of granulebound starch synthesis (GBSS) levels in North Vietnam local rice cultivars. $R G N$., $\mathbf{2 4}$ : $62-64$

Issiki, M., K. Morino., M. Nakajima., R. J. Okagaki., S. R. Wessler., T. Izawa and K. Shimamoto 1998 A naturally occurring functional allele of the rice waxy locus has a GT to TT mutation at the 5' splice site of the first intron. Plant J., 15: 133138

Jahan, M. S., T. Kumamaru, A. Hamid and H. Satoh 2002 Diversity of granule-bound starch synthase (GBSS) level in Bangladesh rice cultivars. $R G N$., 19: $69-71$

Koutroubas, S. D., F. Mazzini, B. Pons and D. A. Ntanos 2003 Grain quality variation and relationship with morphological traits in rice (Oryza sativa L.) genetic resources in Europe. Field Crops Res., 86: 115-130

Kumar, G. R., K. Sakthivel, R. M. Sundaram, C. N. Neeraja, S. M. Balachandran, N. S. Rani, B.C. Viraktamath and B.C. Madhav 2010 Allele mining in crop: Prospects and potentials. Biotech adv., 28: 451-461

Kuo, Y. C and S. C. Hsien 1982 Genetical studies on grain characters in rice. J. Agric. Res. China., 31: 177-186

Laemmli, U. K. 1970 Cleavage of structural proteins during the assembly of the head of bacteriophage T4. Nature., 227: 680-685

Larkin, P. D., A. M. McClung, N. M. Ayres and W. D. Park 2003 The effect of Waxy locus (Granule Bound Starch Synthase) on pasting curve characteristics in specialty rices (Oryza sativa L.). Euphytica., 131: 243-253

Larkin, P. D. and W. D. Park 2003 Association of Waxy gene single nucleotide polyporpHisms with starch characteristics in rice (Oryza sativa L.). Mol Breeding., 12: 335-339

Liu, L., X. Ma, S. Liu, C. Zhu, L. Jiang, Y. Wang, Y. Shen, Y. Ren, H. Dong, L. Chen, X. Liu, Z. Zhao, H. Zhai and J. Wan 2009 Identification and characterization of a novel Waxy allele from a Yunnan rice landrace. Plant Mol Biol., 71: 609-626

Melissa, A. F., S. R. McCouch and R. D. Hall 2008 Not just a grain of rice: the quest for quality. Trends Plant Sci., 4: 133-138

Mikami, I., M. Aikawa, H. Y. Hirano and Y. Sano 1999 Altered tissue-specific expression at the $\mathrm{Wx}$ gene of the opaque mutants in rice. Euphytica., 105: 91-97
Mikami, I., N. Uwatoko, Y. Ikeda, J. Yamaguchi, H. Y. Hirano, Y. Suzuki and Y. Sano 2008 Allelic diversification at the $W x$ locus in landraces of Asian rice. Theor Appl Genet., 116 979-989

Myers, A., M. K. Morell, M. G. James and Ball 2000 Recent progress toward understanding biosynthesis of the amylopectin crystal. Plant Physiol., 122: 989-997

Nakagahara, M and T. Nagamine 1986 Spontaneous occurrence of low amylose genes and geographical distribution of amylose content in Asian rice. RGN., 3: 77-83

Nakamura, Y 2002 Towards a better understanding of the metabolic system for amylopectin biosynthesis in plants:-Rice endosperm as a model tissue. Plant Cell Physiol., 43: 718725

Nakamura, Y., A. Sato and B. O. Juliano 2006 Short-chain-length distribution in debranched rice starches differing in gelatinization temperature or cooked rice hardness. Starch/ Starke., 58: 155-160

Nishi, A., Y. Nakamura, N. Tanaka and H. Satoh 2001 Biochemical and genetic analysis of the effects of amyloseextender mutation in rice endosperm. Plant Physiol., 127: 459-472

Okuno, K., M. Katsuka, H. Nakayama, K. Ebana and S. Fukuoka (1996), International collaboration on plant diversity analysis. In: H. Seko (ed.), Proceeding of the $4^{\text {th }}$ International Workshop on Genetic Resources, MAFF, Japan: 157-169

Olsen, K. M and M. D. Purugganan 2002 Molecular evidence on the origin and evolution of glutinous rice. Genetics., $\mathbf{1 6 2}$ 941-950

Rathi, S., R. N. S. Yadav and R. H. Sama 2010 Variability in grain quality character of upland rice of Assam, India. Rice Science 17(4): 330-333

Sano Y. (1984) Differential regulation of waxy gene expression in rice endosperm. Theor. Appl. Genet. 68: 467-473

Satoh, H., Ronald R. X and T. C. Katayama (1990) On amylose content of cultivated rice collected in Madagasca, 1988 Kagoshima University Research Center South Pacific, Occasional Papers., 18: 83-91

Satoh, H., A. Nishi, N. Fujita, A. Kubo, Y. Nakamura, T. Kawasaki and T. W. Okita 2003 Isolation and characterization of starch mutants in rice. J Appl Glycosci., 50: 225-230

Satoh, H., K. Ohtsubo and Y. Nakamura 2004 Mutation in seed reserves and its use for improving grain quality in rice. In Rice is life: scientific perspectives for the $21^{\text {st }}$ century: 160-161

Satoh, H., A. Nishi, K. Yamashita, Y. Takemoto, Y. Tanaka, Y. Hosaka, A. Sakurai, N. Fujita and Y. Nakamura (2007) Starch branching enzyme I-deficient mutation specifically affects the structure and properties of starch in rice endosperm. Plant Physiol., 133: 1111-1121.

Smith, A. M., K. Denyer and C. Martin 1997 The synthesis of the starch granule. Annual Rev Plant Physiol and Plant Mol Bio., 48: 67-87.

Yano, M., K. Okuno, H. Satoh and T. Omura 1988 Chromosomal location of genes conditioning low amylose content of endosperm starches in rice, Oryza sativa L. Theor Appl Genet., 76: 183-189

Takeda, T and S. Hizukuri 1987 Structures of rice amylopectin with low and high affinities for iodine. Carbohydr. Res. 168: $79-88$

Wang, Z. Y., F. Q. Zheng, G. Z. Shen, J. P. Gao, D. P. Snustad, M. G. Li, J. L. Zhang and M. M. Hong 1995 The amylose content in rice endosperm is related to the post-transcriptional regulation of the waxy gene. Plant J., 7: 613-622

Zeng, Y., S. Shiquan, L. Zichao, Y. Zhongyi, W. Xiangkun, Z Hongliang and W. Guosong 2003 Ecogeographic and genetic diversity based on morphological characters of indigenous rice (Oryza sativa L.) in Yunnan, China. Gent. Resour. Crop Evalut., 50: 567-577 